MATEC Web of Conferences 53, 01055 (2016)

DOI: $10.1051 /$ matecconf/20165301055

C Owned by the authors, published by EDP Sciences, 2016

\title{
The use of Transaction Costs Theory in Interorganizational Design
}

\author{
Jasmina Ćetkovićc ${ }^{1, a}$, Slobodan Lakić ${ }^{1}$, Miloš Knežević ${ }^{2}$, Miloš žarković ${ }^{3}$ and Tatiana Sazonova ${ }^{4}$ \\ ${ }^{1}$ Faculty of Economics, University of Montenegro, 81000 Podgorica, Montenegro \\ ${ }^{2}$ Faculty of Civil Engineering, University of Montenegro, 81000 Podgorica, Montenegro \\ ${ }^{3}$ Erste Bank AD Podgorica, 81000 Podgorica, Montenegro \\ ${ }^{4}$ St. Petersburg State University of Architecture and Civil Engineering, 2-Krasnoarmejskaja, 4, Saint-Petersburg, 190005, Russia
}

\begin{abstract}
This paper analyzes the basics of economics of transaction costs, which grew into a suitable and practical tool to explore the wide problems in the domain of different sciences. The emphasis in this paper is placed on the use of economics of transaction costs in the determination of the growth limits and optimization of its organizational structure. This paper further explores the implications of the economics of transaction costs on contemporary forms of inter organizational design.
\end{abstract}

\section{Introduction}

For a particular product or a service to cross the boundaries of an organizational system or any part thereof it is necessary to perform an activity or set of activities that are called transactions.

The agreed price of the goods or services is not the only cost, because transactions conducted in the market are not free. Realization of transaction activities has an effect on the occurrence of transaction costs, which some authors call "transition costs" and represent the cost of preparing and controlling the movement of goods and services in the market or within the organizational system. Williamson defined transaction costs as the costs of planning, adapting and monitoring achievement of objectives in the case of alternative governance structures [1]. Rougher definitions of transaction costs under transaction costs include all costs except production costs - associated with the transactions.

Size of transaction costs depends on the type of transaction and its complexity. In the modern world, transaction costs increase as a result of costly information that are asymmetrically distributed among the groups that exchanged them. The limitations of certain cognitive capacity and the lack of information are the basic assumptions of the new institutional theory on which grounds the theory of transaction costs has been created. New institutional economics has begun to engage in defining research questions related to the structure of $\mathrm{t}$ he economic systems and research how to adapt traditional economic methods in order to explore these questions. Coase's historical essay from 1937 [2] is a classic example of this approach. Coase questioned why some transactions take place on the market, and others within the company, and what factors determine the allocation of transactions between these two spheres. Thus, the idea of costs of transactions was born which is then transformed into the concept of transactional costs which is now a key part of the economics of institutions.

\section{The theory of transactions costs as the basis of the modern economics}

The theory of transaction costs is the foundation of modern economics. Until the 70s of the last century many, more or less wellknown economists considered this theory as controversial or wrong. The term "economics" was first used in the 20 s of last century in the A. Marshall's book "Principles of Economics" [3] who is known as the originator of the Cambridge School and one of the opponents of unlimited effects of laissez-faire. He has under this term marked the science that has studied the economic problems which were previously dealt by the political economy. Neoclassics have defined economics as the science that studies the allocation of resources by human societies, mutual concurrence to each other.

The basis of modern economics presents a series of works synthesized in the theory of transaction costs, which is the basis of economics of transaction costs as well as contemporary economics. The economics of transaction costs studies the transaction costs of goods and services among market participants, as well as Demsetz noticed there is a cost of using "price mechanism" [4]. This theory has grown on the foundations of a new trend of economic thought in the 70s of the last century - the "new institutionalism" which founder is the Nobel laureate R.H. Coase. This economic thought was created as a response to the old "American institutional school."

The economics of transaction costs has grown into usable practical tool, suitable to explore the broad types of problems in different sciences. At the same time, it is also used in the study of the size of the company, to establish the limits of growth of the

\footnotetext{
${ }^{\text {a }}$ Corresponding author : jasmina@ac.me
}

This is an Open Access article distributed under the terms of the Creative Commons Attribution License 4.0, which permits unrestricted use, distribution, and reproduction in any medium, provided the original work is properly cited. 


\section{MATEC Web of Conferences}

company, and the boundaries of the market where the company performs.

R. H. Coase wrote his groundbreaking work entitled The Nature of the Firm back in 1937 in England. Later, transferring to the United States, his dilemmas are shared with the Chicago School, which was strongly influenced by Marshall's views. This is particularly evident in 1960 when he published a paper entitled The Problem of Social Costs in which he made a significant step forward compared to Pigoua (after Marshall's, the spiritual leader of the Cambridge school). Pigoua's understanding of solving problems through government interventions and legal system was enhanced with a new understanding of resolving relationship among market players in terms of opportunity cost, legal liability and property rights.

The term "economics of the new institutionalism" or shorter "new institutionalism" is associated with the science of the R.H. Coase, A.A. Alchian, H. Demsetz, O.E. Williamson and others who deal with the problem of transaction costs in the market, as well as the rights of ownership and responsibility in economic relations (such as H.A. Simon, E.F. Fama, M.C. Jensen, S.G. Winter, et al.). As a leading representative of the school of "new institutionalism" Coase was awarded with the Nobel Prize in 1991 for his contribution. However, Coase's noticed that when making a decision on the question of "make or buy" market price is not the only deciding factor. Important, often the deciding factor are significant transaction costs, which at that time were high and large companies rather decided to produce by themselves than to indulge in the purchase of products that have followed the high transaction costs of the procurement coordination.

The theory of transaction costs is essentially a theory of the firm which is constantly trying to respond to the question - why the company exists? The essence of this theory is the replacement of the price mechanism with more efficient performance of the transaction of goods or services under alternative institutions, under which the company is understood and any other structure (vertical integration, auction etc.) in order to reduce transaction costs. Coase's initial assumption is the assumption of the existence of the company due to the existence of transaction and marketing costs which they cannot reduce to a minimum. If these costs are equal to the cost of using the price mechanism, the existence of the company would lose the purpose.

Shift in his perception, Coase gave in his work The Problem of Social Cost in which he presented a new argument - the right of ownership of a particular property will not affect the efficiency of the allocation of goods, unless there are transaction costs of negotiating - this postulate was later called the Coase Theorem.

A further contribution to the development of the theory of transaction costs was given by O. Williamson. He perceives transaction costs as the costs of planning, adapting and monitoring the execution of the objectives in the case of alternative governance structures [1]. Williamson noted that the company has its own role in the economic system if the transactions are organized into companies at lower costs than those at which the transactions took place over the market. Market imperfections, the complexity of the organizational structure and the number of participants in the market are the key factors of the size of transaction costs. The dimension of market imperfections is a consequence of bounded rationality and opportunistic behavior of participants. He found a clear link between the three dimensions of the transaction - specific assets, uncertainty and frequency of transactions. The higher the degree of specificity is, the greater the need to organize transactions internally, within the hierarchy/firm. For an organization it would be more profitable to meet the requirement within its borders, than to provide it through the purchase on the market. Identification of appropriate methods for objective decisions about what should be internal and external transactions is the primary task of the analysis of transaction costs. Furthermore, due to the high degree of uncertainty in the behavior of parties involved in the transaction, the transactions are often internalized. Also, the greater the degree of frequency of transactions, the lower transaction costs is within the hierarchy/firms than the costs of market transactions.

The theory of transaction cost has defined the basis for determining the company growth limits. Whether a transaction is carried out within the firm or on the market, it depends on the relationship between costs incurred as a result of the transaction on the market and the cost of carrying out the same transactions within an organizational form. Organization size limit is determined by the volume of those transactions whose overspending leads to higher transaction costs within the company in relation to the costs of carrying out the same transactions in the market. With this kind of analysis we are able to determine the economic limits of the company growth, or economically feasible solution of vertical and horizontal expansion of activities within a single organizational system. The main objective of the theory of transaction costs is to minimize them through the establishment of any management structure that leads to the realization of the basic objective.

Use-value theory of transaction costs does not decrease the indisputable practical situations in which firms carry out transactions within the hierarchy even if the transaction costs of market transactions are zero, guided with the interests of greater reliability, dependence reduce of unpredictable market, profitability rate increase by exploiting effects of economies of scale and etc.

\section{The use of Transaction costs theory in interorganizational design}

One of the theoretical foundations of modern forms of interorganizational relations is the theory of transaction costs. Start of the theory of transaction costs use in the issue of organizational restructuring is linked to the works of Commons in 1934. In the transaction costs, he recognized factor and measure of the efficiency of the organizational structure [5]. Next, Coase concluded that the organizations are basically an alternative to the market and variable organization boundaries depend on the analysis of transaction costs which indicates the economic rational horizontal and vertical expansion activities. Essentially, in this analysis decisions about opening new businesses or retaining and developing certain parts of the company should be based. That solves one of the major issues, such as the question of optimization of the organizational structure.

J.C. Jarillo in his work On Strategic Networks [6] pointed on the use of the theory of transaction costs in organizations interorganizational design. Specifically, in addition to the extremes "produce or buy", he identifies the third option which is realized through various forms of cooperation between organizations in the field interorganizational design. Jarillo recognizes relations of cooperation between the companies as a source of competitive advantage. He pointed out to the greater efficiency of 
networks or alliances in relation to the hierarchies/firm and the market in terms of minimizing transaction costs. In this sense competitive and cooperative aspects of the behavior of companies are identified as complementary aspects of the behavior of a single reality.

Modern and intensified forms of cooperation between organizations relativize the importance of the opportunistic behavior of actors' phenomenon and the concept of the high cost of monitoring market transactions. Through modern and different types of networks between organizations a new mechanism for coordinating activities - trust and predictability is establishing, while conflicts prevention is resolved by balancing the interests of network elements [7]. The network forms of organization according to Powell are characterized by reciprocal communication patterns and the exchange representing sustainable economic organization. In Tab. 1 below, Powell presented a comparative overview of the differences between the basic characteristics of the markets, networks and hierarchy/company.

Table 1. A comparative overview of the differences between the basic characteristics of the markets, networks and hierarchy/company

\begin{tabular}{|c|c|c|c|}
\hline Key Features & Market & Hierarchy & Network \\
\hline Normative Basis & Contract - property Rights & Employment Relationship & $\begin{array}{c}\text { Complementary } \\
\text { Strengths }\end{array}$ \\
\hline Means of Communication & Prices & Routines & Relational \\
\hline $\begin{array}{c}\text { Methods of Conflict } \\
\text { Resolution }\end{array}$ & $\begin{array}{c}\text { Haggling - resort to courts } \\
\text { for enforcement }\end{array}$ & $\begin{array}{c}\text { Administrative fiat - } \\
\text { Supervision }\end{array}$ & $\begin{array}{c}\text { Norm of reciprocity - } \\
\text { Reputational concerns }\end{array}$ \\
\hline $\begin{array}{c}\text { Degree of Flexibility } \\
\text { Amount of Commitment } \\
\text { Among the Parties }\end{array}$ & Low & Medium to High & Medium to High \\
\hline Tone or Climate & Precision and/or Suspicion & Formal, bureaucratic & Open-ended, mutual benefits \\
\hline Actor Preferences or Choices & $\begin{array}{c}\text { Repeat transaction } \\
\text { (Geertz, 1978) } \\
\text { Contracts as hierarchical } \\
\text { documents } \\
\text { (Stinchcombe, 1985) }\end{array}$ & $\begin{array}{c}\text { Informal organization } \\
\text { (Dalton, 1957) } \\
\text { Market-like features: profit } \\
\text { centers, transfer pricing } \\
\text { (Eccles, 1985) }\end{array}$ & Status Hierarchies \\
\hline Maxing of Forms & $\begin{array}{c}\text { Dependent } \\
\text { Multiple Partners }\end{array}$ \\
\hline
\end{tabular}

The modern practice of interorganizational relations has overcome the limitations of traditional transactional arrangements of supplying and servicing, opening up a space for more complex forms of interorganizational cooperation and relations. Through modern ways of networking organizations are trying to achieve synergetic effects compiling internal, hierarchical and external coordination of market relations. Equity incentives under various forms of interorganizational relationships contribute to minimization of the opportunity costs.

However, the limits of growth are not something that cannot be reached. With the growing size of the organization, costs of coordinating activities and managing tempered relations are growing as well as the price of the size of the organizational system. One of the ways to counteract the increasing costs of coordination and management in relation to the use of internal production is the relocation of activities that are not of primary (non-core) and are called outsourcing. However, outsourcing companies must have access to a sufficiently large and quality market supplier which cannot always be safely counted.

In this regard, the hybrid contract forms between organizations occur in response to the transaction which marks the specificity of assets, while vertical integration remains in force with transactions that are characterized by strong bilateral dependence. Classic contracts represent a form of market coordination relationships in simple market transactions while relational contracts are the basis for many forms of interorganizational forms that are between all extremes (markets and hierarchy/firm).

The cooperation forms that facilitate cooperation and integration between different levels of organization are called the strategic alliances. The forms of cooperation that have characteristics of network and hierarchical organizations are the franchise arrangements and joint ventures. The highest degree of vertical integration and the internal value creation is achieved by forming mergers, acquisitions and hierarchically organized independent organizations. Typical forms of inter-organizational networks are based on vertical integration as mergers and acquisitions. The highest degree of vertical integration is achieved through mergers and acquisitions. With the growth of the transaction which subject is complex, non-standard product, organization development will be directed towards the vertical differentiation or integration in order to minimize management costs as a result of bounded rationality as a kind of transaction costs. In this way vertical integration has primacy over contracting.

Williamson has analyzed a number of benefits from an integration organizations trends such as better control over the assets, less obvious problem of informational imperfections, increasing the sense of belonging to the organization which leads decreasing the need for opportunistic behavior and so on.

On the other hand, Coase analyzed the factors of limiting the growth boundaries of the organization - increasing the cost of planning activities of the company due to an increase in the number of parts of the company, the likelihood of poor allocation of production resources with the growth of the number of transactions between the company and the possibility of monopoly of the market due to competition of choking firms growth [8]. 


\subsection{Contemporary theoretical consensus - outsourcing as a form of interorganizational relation}

Unexpectedly low rates on return that coorproations have begun to realize at the end of the last century sent a signal to organizations in order to review the organizational design. The positive effects of economies of scale, expanding the product range, high market share, and greater control over the sources of resources and distribution channels through large integration among organizations were absent compared to the expected. Contemporary theoretical consensus has given birth to the opposite recommendation - reducing the size of the "real" measure (rightsizing) company focus on small core activities.

One of the basic organizational trends becomes transmission of peripheral activities to third parties, except for the activities that are most important and unique and provide the company an edge over competitors (competitive advantage) [9]. Unlike traditional agreements on procurement and outosourcing are characterized by long-term business relationship and a high level of shared risk. In practice, there are various forms of outsourcing, the forms that include targeted, short-term forms of business cooperation, to forms of business cooperation in which they share responsibility and risks in the business. There are forms of outsourcing in which the tasks are delegated to a third party within the borders of one country but the forms which delegate abroad (offshore outsourcing).

Contemporary forms of outsourcing are not orientated to improve the efficiency of a single function or activity but on the reconfiguration of the entire business process which enhances the value of the organization as a whole as well. Thus outsourcing is recognized as a way for the implementation of structural changes in the organization that includes tactical (short-term) and long term (strategic) benefits. Short-term effects might be usage of the effects of economies of scale and resolution of financial problems and the long-term strategic are showing focus of the organization on key competences [10].

However, besides the positive effects, outsourcing produces certain drawbacks such as increased dependence on suppliers, loss control, employee redundancy, increased costs due to the "hidden" costs of outsourcing, etc.

Furthermore, the literature points to the other traps of outsourcing: the lack of managament commitment, lack of communication plan, the minimum knowledge and experience of suppliers, non-recognition of outsourcing risk, ignoring cultural differences and so on [11]. Therefore, the organization needs, during the contract design contract for outsourcing, in the best possible way to protect itself against all possible risks [12].

Due to a lack of outsourcing in the literature, the term backsourcing is introduced implying a "return" in the organization of activities that were the subject of outsourcing as a result of various factors [13].

It is certain that the company will opt for outsourcing when other organizations can perform the same activity with lower costs due to the use of the effects of economies of scale [14]. Some authors note that today outsourcing is used as a tactical way out of financial difficulties [15]. Although the biggest beneficiaries of outsourcing are larger companies, some authors state that the effects of outsourcing are biggest in small companies [16], because small companies cannot reveal greater effects of economies of scale.

The basic premise of successful outsourcing is correct identification of core competencies. Displacement, due to errors, core competencies "outside" of the competitive advantage of the organization can be permanently lost [17].

\subsection{Continued use of the theory of transaction costs at interorganizational design - strategic alliances, joint ventures, mergers and acquisitions}

Avoiding opportunity costs characteristic for transactions conducted through the market happens with establishing of interorganizational relationships or partnerships. One of the current forms of partnerships is strategic alliances.

On the possibility of applying the theory of transaction costs on the strategic alliance Carlos Jurrilo was the first to point out. He noticed that the cooperative behavior of an organization becomes a modern success factor. He recognizes the theoretical framework for the study of competitive/market and cooperative aspects of the company as compatible aspects of a single reality. In addition, cooperative relationships become the source of its competitive strength. At that point, Jarillo developed the concept of strategic networks as a tool for understanding cooperative relations among firms and analyze their role in creating the strategy of the company. Analyzing networks in relation to the market and hierarchy (as extreme models of internal and external relations) Jurrilo defined several characteristics of strategic networks [6]: hybrid mechanisms, trust and predictability as coordination mechanisms, balancing of interests as a mechanism to overcome the conflicts, mutual dependence as a preference or choice of actors, semiformal degree of formalization, mutual adaptation as a model of integration, etc. The economic limits of firm size are determined by the scope of activities that may be exceeded to overcome the costs of market transactions or in cooperation with another company. Often, when it reaches the limits of the economic size of the company, the company expands its business in a manner that is pooled with other companies.Strategic alliances are in the center of the spectrum of different organizational forms.

The role of strategic alliances is in cooperation facilitation and different degrees of integration between the companies which often leads to overgrowth in mergers and acquisitions. Competitive pressures have encouraged firms to seek additional sources in cooperation with others. Today participation in a number of strategic alliances is inevitable.

These cooperative arrangements, focused on the realization of common strategic objectives, which may lead to significant and lasting exchange, sharing and joining of new development of knowledge, products, services or technologies, allow access to complementary competencies that are expensive to develop within a company. As the deepest form of cooperation, the strategic alliance would have to deduct a portion of the autonomy from the partners and to leave a significant part of the autonomy to business partners [18] which are often direct competitors to each other. The famous and successful examples of such alliances are Sony and Ericsson (area of mobile telephony) or Star Alliance and United Airlines (area of air travel).

The structure of strategic alliances varies from medium and long term aspects (capital joint ventures and minority equity alliances) to the short and medium term structure (bilateral and unilateral alliance). The degree of organizational integration is the highest at the first structure and significantly lower in other structures of the alliance which is primarily a result of its ownership 
structure. In the capital there is a common joint venture equity and minority equity alliances with one-way or reciprocal capital ownership. In the capital joint ventures there is a common equity and minority equity alliances with one-way or reciprocal capital ownership. In bilateral and unilateral alliances there is no joint ownership partner. Some authors [19] are ranking rigorous strategic alliances, from transaction, over medium to permanent relations, such as cartels.

The joint venture involves a type of strategic partnership in which merger of a portion of resources between two or more organizations occurs in order to create a separate organization with common ownership.

The share of resources is often equal but different from a purely financial participation through participation license or brand. Studies show that the rate of degradation of the joint venture, as a high-risk forms of partnership, declined in the late 20th century to less than $50 \%$. The main motives of making the joint venture, by many authors, are recognized as risk sharing in the implementation of a business idea and the realization of access to foreign markets. Partnership motives may be usage of the effects of economies of scale (production and distribution) and economy of wide.

Mergers involve a combination of the two organizations whereby one organization ceases to exist, while acquisitions mark to take control of another organization, where the merger organization becomes majority owner and mergee organization does not necessarily exist. Much of the research that was done in the world show a higher number of motives for the formation of mergers and acquisitions ranging from increased market share and its preservation, reduce competition and increasing revenues, purchasing technology to the rapid growth and use of multiple effects of synergy [20].

In the early 20th century, Bower, based on research conducted in the United States, provided a fairly comprehensive range of motivational factors for the case company acquisition. Results of this deep research showed that acquisitions occur for five reasons:

- $\quad$ to deal with overcapacity through consolidation in mature industries;

- $\quad$ to roll-up competitors in geographically fragmented industries;

- $\quad$ to extend into new products or markets;

- $\quad$ as a substitute for R\&D and

- $\quad$ the use of eroded industrial boundaries to create new industries [21].

Results arising as a result of M\&A, according to Robert F. Bruner can be measured over at least seven elements [22]:

- Creation of market value;

- Financial stability,

- $\quad$ Improved strategic position;

- $\quad$ Organizational strength;

- $\quad$ Enhanced ,brand“;

- $\quad$ Observance of the letter and spirit of ethical norms and laws and

- Improved process. 3.

Mania of mergers and acquisitions was strongly expressed in 80 s and 90 s of the twentieth century [23] as shown in Table 2 and

Table 2. Completed acquisitions in Western Europe, 1984-1989

\begin{tabular}{|c|c|c|}
\hline Year & Total No & Value [£m] \\
\hline 1984 & 596 & 7.050 \\
\hline 1985 & 1.138 & 13.414 \\
\hline 1986 & 1.565 & 29.045 \\
\hline 1987 & 2.246 & 36.274 \\
\hline 1988 & 3.361 & 52.659 \\
\hline 1989 & 5.138 & 85.759 \\
\hline
\end{tabular}

Table 3. Acquisitions and mergers by industrial and commercial companies within the UK from 1984 to 1994

\begin{tabular}{|c|c|c|}
\hline Year & No. of companies acquired & Total expenditure, [£m] \\
\hline 1984 & 568 & 5.474 \\
\hline 1985 & 474 & 7.090 \\
\hline 1986 & 842 & 15.367 \\
\hline 1987 & 1.528 & 22.839 \\
\hline 1988 & 1.499 & 27.250 \\
\hline 1989 & 1.337 & 8.329 \\
\hline 1990 & 779 & 10.434 \\
\hline 1991 & 506 & 5.941 \\
\hline 1992 & 432 & 7.063 \\
\hline 1993 & 526 & - \\
\hline 1994 & - & 2.720 \\
\hline 1st quarter & 183 & 1.652 \\
\hline 2nd quarter & 184 & 2.109 \\
\hline 3rd quarter & 154 & \\
\hline
\end{tabular}




\section{MATEC Web of Conferences}

The next wave that swept the business world began in 1998 and marks the internationalization wave of mergers, tackling Europe, Asia (Japan) and America (Canada). Entering in the 21st century and the current state characterizes weakening of this type of activity which was not significantly jeopardized by the previous trends in this area. Last weakening of these activities is primarily a result of a current financial crisis that has significantly affected the functioning of the global financial system. All processes of intense merger activity are characterized by a state of lower interest rates, increase in stock prices and economic expansion. Throughout the history, the experience with the global mergers and acquisitions has not been positive only. At the beginning of the 21st century, Marks and Mirvis analyzing the trends in the establishment and survival of mergers and acquisitions practice stated that three out of four mergers and acquisitions do not achieve the assigned strategic and financial goals [24] because as noted by psychologist Harry Levinson - "when companies merge and acquire, It's a lot like falling and love" [25] In order to improve these processes Marke and Mirvis analyzed the strategic and psychological challenges that organizations have to have and which should solve on the best way in the preparatory phase of this process in order to improve their performance [26-29]. Soon the factor analysis by which the theory tried to explain failures of a large number of mergers and acquisitions evaluated from traditional and rational factors to the soft factors of what the human factors and organizational behavior are [30-33].

\section{Summary}

The basis for determination of the company growth limits, established by the transaction costs theory, served as a guideline and a challenge to the use of the theory of transaction costs in modern interorganizational company design. As the limits of companies' growth can be reached, due to rising costs of coordinating activities and managing tempered relations of growing organizational system, the modern practice of interorganizational relations has opened the possibility of complex forms of interorganizational cooperation and relations. The current financial crisis has opened the issue of business uncertainty, which also revived the need for establishing an adequate vision of firms businesses. In these conditions, it's likely, modern forms of interorganizational relations and cooperation will represent an important means for their realization.

\section{References}

1. O. Williamson, Am. J. Soc., 87, pp. 287-296 (1981)

2. R. H. Coase, Econom. New Ser., 4(16), pp. 386-405 (1937)

3. A. Marshall, Principles of Economics London: Macmillan; Books, p. 376 (1920)

4. H. Demsetz, The Economics of the Business Firm: Seven Critical Commentaries Cambridge University Press, UK, p. 285 (1997)

5. J. R. Commons, Institutional Economics McMillan, p. 385 (1934)

6. J. C. Jurillo, Str. Manag. J., 9, pp. 31-41 (1988)

7. W. Powell, Neither Market Nor Hierarchy: Network Forms of Organization Research in Organizational Behavior, 12, p. 300 (1990)

8. O. Williamson, S. Winter, Oxf. Uni. Pre. p. 327 (1991)

9. M.E. Porter, Competitive Strategy Free Press, New York, p. 361 (1980)

10. A. Douglas, J. Meehan, Outsourcing for business excellence, Tot. Qual. Manag., pp.278-293 (2001)

11. M. Power, C. Bonifazi, K.C. Desouza, J. Bus. Str., 25 (2), pp.37 - 42. (2004)

12. K. Andrade, R.B. Chapman, Insourcing After the Outsourcing, Guide Amacon New York, p. 287 (1998)

13. S.F. Wong, Drivers for IT backsourcing decision IBIMA, 2 (14), pp. 765-779 (2008)

14. A.P. Kakabadse, N. Kakabadse, Eur. Manag. J., 20 (2), pp. 756-764. (2002)

15. M. Johnson, Outsourcing in Brief. London: Butterworth- Heinemann Oxford, p. 186 (1997)

16. A.H. Jumah, D. Wood, UK Comp. W. St., 49 (7), pp. 265 - 275 (2000)

17. C.K.. Prahalad, G. Hamel, Har. Bus. Rev., pp. 765-773 (1990)

18. D. Jolly, Eur. Bus. For. 9, pp. 567-584 (2002)

19. J.R. Harbison, P.P. Pekar, Smart Alliances: A Practical Guide to Repeatable Success, Wiley, p. 176 (1998)

20. P. Shrivastava, J. Bus. Str., 7, pp. 65-76 (1986)

21. J. L. Bower, Not All M\&As Are Alike-and That Matter Har. Bus. Rev., p. 98 (2001)

22. R.F. Bruner, Applied Margers and Acquisititon New York: John Wiley \& Sons, p. 243 (2004)

23. S. Cartwright, C.L. Cooper, Managing Mergers, Acquisition and Strategic Alliances: Integrating People and Cultures Oxford: Butterworth Heinemann, p. 325 (1996)

24. M.L. Marks, P.H. Mirvis, Acad. Manag. Exec., 15(2), pp.745-756 (2001)

25. H. Levinson, Har. Bus. Rev., pp. 81-101 (1970)

26. J. Ćetković, S. Rutešić, M. Zarković, M. Knežević, N. Vatin, Procedia Engineering, 117 (1), $780-790$ (2015)

27. B. Stamatovic, R. Upadhyay, Procedia Engineering, 117 (1), 660-667 (2015)

28. S. Rutešić, J. Ćetković, M. Žarcković, M. Knežević, N. Vatin, Procedia Engineering, 117 (1), $905-915$ (2015)

29. S. Rutešić, J. Ćetković, M. Knežević, M. Žarcković, N. Vatin, Procedia Engineering, 117 (1), $642-650$ (2015)

30. B. Melović, S. Mitrović, A. Djokaj, N. Vatin, Procedia Engineering, 117 (1), 807-812 (2015)

31. K. Strelets, N. Vatin, (2015) Rocznik Ochrona Srodowiska, 17 (1), 104-112 (2015)

32. L. Muravyeva, N. Vatin, Applied Mechanics and Materials, 635-637, 451-456 (2014)

33. S. Ognjenovic, R. Donceva, N. Vatin, Procedia Engineering, 117 (1), 549-555 (2015) 